\title{
PROMOÇÃO DO LETRAMENTO ACADÊMICO CONTRA A PRÁTICA DO PLÁGIO
}

\section{FOSTERING OF THE ACADEMIC LITERACY AGAINST PLAGIARISM PRACTICE}

\author{
Renata Ferreira $\operatorname{Costa}^{59}$ \\ Cinthia Almeida Lima ${ }^{60}$
}

\begin{abstract}
RESUMO: A prática do plágio é frequente e deliberada na academia, mas não legitimada no discurso científico, baseado na noção de autoria, de originalidade e de recorrência a conhecimentos e discussões formulados anteriormente, que precisam ser citados e referenciados e a partir dos quais se produz uma reflexão pessoal e original. Diante desse cenário, discussões e propostas de intervenção em relação ao plágio na academia são extremamente relevantes e necessárias, uma vez que esse tipo de atitude, que dissimula o texto-fonte e oculta o nome do autor original, prejudica não só o próprio plagiário, que se vê diante da reprovação moral e descrédito da comunidade científica, mas também a reputação da instituição à qual está associado. Desta forma, este trabalho visa discorrer sobre a noção de plágio e suas consequências nocivas para o desenvolvimento da ciência e promover uma discussão em torno das dificuldades de leitura e escrita dos alunos e das competências necessárias para o seu letramento acadêmico. A pesquisa realizada insere-se no campo dos estudos da Linguística Aplicada e fundamenta-se nos conceitos de modelo ideológico de letramento e de letramento acadêmico, desenvolvidos no âmbito dos "Novos Estudos do Letramento" (STREET, 1984, 2014; LEA; STREET, 1998, 2006).
\end{abstract}

PALAVRAS-CHAVE: Letramento Acadêmico. Escrita Acadêmica. Integridade Científica. Plágio. Direitos Autorais.

ABSTRACT: The practice of plagiarism is frequent and deliberate in the academy, but not legitimized in scientific discourse, based on the notion of authorship, originality and recurrence of previously formulated knowledge and discussions that need to be cited and referenced and from which a personal and original reflection. Given this context, discussions and proposals for intervention in relation to plagiarism in Academy are extremely relevant and necessary, since this type of attitude, which conceals the source text and hides the original author's name, harms not only the plagiarist himself, which is seen before the moral reprobation and discredit of the scientific community, but also the reputation of the institution to which it is associated. Therefore this work aims to discuss notions of plagiarism and its harmful consequences for the development of science as the same as to promote a conversation about the reading and writing difficulties of students and the skills needed for their academic literacy. The research carried out is inserted in Applied Linguistics field and it is also based on the concepts of ideological model of literacy and of academic literacy that were developed under "New Studies of Literacy" (STREET, 1984, 2014; LEA; STREET, 1998, 2006).

KEYWORDS: Academic Literacy. Academic Writing. Scientific Integrity. Plagiarism. Copyright.

\section{Introdução}

A Modernidade inaugurou a "sociedade do conhecimento", na qual, segundo Carvalho e Kaniski (2000, p. 35), "o saber ocupa o papel central, acompanhado de uma nova classe de trabalhadores, a dos trabalhadores do conhecimento". Esse tipo de trabalhador se afasta do conceito clássico de "humanista" (humanistae) ou "homem de letras", também chamado

\footnotetext{
59 Doutora em Letras pela Universidade de São Paulo. Professora Adjunta do Departamento de Letras Vernáculas, do Mestrado Profissional em Letras e do Mestrado Profissional em Ciência da Informação da Universidade Federal de Sergipe. Líder do Grupo de Estudos Filológicos em Sergipe - GEFES/CNPq. E-mail: renataferreiracosta@yahoo.com.br

${ }^{60}$ Mestranda em Filosofia, na linha de pesquisa "Conhecimento e Linguagem", pela Universidade Federal de Sergipe. Advogada. Membro do Grupo de Estudos Filológicos em Sergipe - GEFES/CNPq. E-mail: cinthialimaadv@gmail.com
} 
"polígrafo", o intelectual autônomo que domina um vasto campo do saber, capaz, portanto, de escrever sobre uma diversidade de assuntos.

A partir do século XX, assiste-se à generalização do processo de especialização, que, particularmente no âmbito educacional (escolas e universidades), "produziu estudiosos com um conhecimento bem mais limitado que o dos antigos (ainda que a menor amplitude tenha sido compensada pela maior profundidade)" (BURKE, 2003, p. 20).

A formação universitária contemporânea se dá nesse contexto de fragmentação do conhecimento, de modo que os sujeitos envolvidos no processo de ensino e pesquisa não se dão conta da amplitude das áreas do saber e suas articulações. Assim, como ressalta Pereira (2014), "nessa construção do conhecimento, o seu avanço se dá pela pesquisa especializada. Ele é tanto mais rigoroso quanto mais restrito for o seu objeto".

No bojo dessa especialização assiste-se nos últimos cinquenta anos a um salto significativo da pesquisa científica no Brasil, em parte pela consolidação da pós-graduação nas universidades, como aponta o Fórum de Reflexão Universitária em artigo publicado no Caderno Temático do Jornal da Unicamp (FÓRUM, 2002, p. 1). Desse modo, em tempos de sociedade do conhecimento ou da informação, a realidade da produção acadêmica se dá em torno da cultura do publish or perish, cujas consequências são o produtivismo acadêmico, o controle da pesquisa e a quantidade de publicações em periódicos indexados nas melhores bases de dados e com índices de impacto significativos.

\begin{abstract}
Essa pressão para escrever e publicar tem levado alunos, professores e pesquisadores universitários a um esforço concentrado na elaboração de textos de qualidade na forma de artigos para periódicos acadêmicos e livros para editoras como meio de assegurar espaço profissional. Desse modo, na cultura acadêmica, a produtividade intelectual é medida pela produtividade na publicação (MOTTA-ROTH; HENDGES, 2010, p.13).
\end{abstract}

Nesse cenário, também, mas não só, como consequência do "publique ou pereça", assoma a proliferação de uma prática dolosa aos direitos autorais e à integridade científica, o plágio, uma das preocupações atuais dos pesquisadores realmente comprometidos com suas produções, de universidades e das agências de fomento à pesquisa. A exigência para produzir e publicar em quantidade e, assim, aumentar seu Curriculum Lattes, conseguir financiamentos para as pesquisas, manter-se nos programas de pós-graduação e obter reconhecimento público, abre espaço para que pesquisadores desonestos copiem ou dissimulem textos alheios ou próprios, mesmo conscientes de que essa é uma prática recriminada na academia, porque fere a integridade científica, e criminosa diante da lei, porque atinge os direitos autorais.

No entanto, nem todos os sujeitos envolvidos no processo de produção científica, principalmente os estudantes, possuem as habilidades e competências necessárias para a construção do discurso científico, que, especializado, demanda um letramento social específico. Assim, outra motivação para a ocorrência do plágio na academia é o desconhecimento do aluno do processo de leitura analítica e da escrita científica, legitimada pela recorrência a ideias formuladas anteriormente e a indicação e identificação das fontes de tais ideias, de modo que, em seu percurso na universidade, acaba por produzir textos ausentes de citações e referências, o que se configura como plágio.

A prática do plágio é frequente e deliberada na academia, mas não legitimada no discurso científico, baseado na noção de autoria, de originalidade e de recorrência a conhecimentos e discussões formulados anteriormente, que precisam ser citados e referenciados e a partir dos quais se produz uma reflexão pessoal e original. Desta forma, este trabalho, inserido no campo dos estudos da Linguística Aplicada e fundamentado nos conceitos de modelo ideológico de letramento e de letramento acadêmico, desenvolvidos 
no âmbito dos "Novos Estudos do Letramento" (STREET, 1984, 2014; LEA; STREET, 1998, 2006), tem como objetivo discorrer sobre a noção de plágio e suas consequências nocivas para o desenvolvimento da ciência, promover uma discussão em torno das dificuldades de leitura e escrita dos alunos e das competências necessárias para o seu letramento acadêmico, assim como apresentar as ações educativas que vêm sendo promovidas na Universidade Federal de Sergipe para o letramento dos discentes, como forma de coibir o plágio, com atenção especial ao projeto de extensão em andamento "Plágio Acadêmico: o que é e como evitá-lo".

\section{Considerações sobre Plágio Acadêmico}

Um dos grandes desafios para o docente da atualidade, seja no ensino fundamental, médio ou universitário, é lidar com a cópia literal ou dissimulada, intencional ou não, de textos e trabalhos, prática que se intensificou com o advento da internet e que compromete o aluno, a instituição à qual ele está vinculado e ainda ameaça a própria qualidade do ensino.

Segundo Jorge (1997, p. 417), é no final do século XVIII e durante a primeira metade do século XIX que, textualmente, "a questão do plágio se coloca insistentemente sobre as 'letras', as regulamentações econômicas e o discurso jurídico". Em relação a este último campo, o do Direito, é quando surge a necessidade de definir o plágio para enquadramento legal. No entanto, no Brasil, a lei 9.610, de 19 de fevereiro de 1998, que regulamenta os direitos autorais, não deixa claro os limites ou os contornos definidores do que seja plágio.

A lei considera como obras intelectuais protegidas, no art. $7^{\circ}$, "as criações do espírito, expressas por qualquer meio ou fixadas em qualquer suporte, tangível e intangível, conhecido ou que se invente no futuro" (BRASIL, 2018a). No art. $8^{\circ}$ está expresso que "não são objeto de proteção como direitos autorais (...) as idéias (...) e o aproveitamento industrial ou comercial das idéias contidas nas obras" (BRASIL, 2018a). Além da obra em si, a lei também assegura, no art. 10, a proteção ao título, "se original e inconfundível com o de obra do mesmo gênero, divulgada anteriormente por outro autor" (BRASIL, 2018a). Assim, é na expressão "criações do espírito", uma delimitação, de certa forma imprecisa, que reside a falta de definição do plágio, que, na verdade, não existe juridicamente, ele é um termo da crítica literária.

Dessa forma, surge o problema da caracterização jurídica do termo plágio, de modo que os juristas, procurando esclarecer a noção, formularam definições que servem de apoio ao Direito Autoral:

Não é o plágio a mera cópia ou reprodução servil da obra alheia, é algo de mais sutil: é um aproveitamento da essência criativa da obra anterior, embora apresentada com roupagem diversa.

O plágio só surge quando a própria estruturação ou apresentação do tema é aproveitada. Refere-se pois àquilo a que alguns autores chamam a composição, para distinguir quer da idéia quer da forma (ASCENSÃO, 1980, p. 13).

Haverá plágio sempre que a obra alheia for apresentada como própria, seja total ou parcialmente, desde que a obra assim fraudulentamente apresentada se manifeste na mesma forma de expressão da obra plagiada. Assim, por exemplo, haverá plágio quando alguém faz publicar como sua a obra de outrem, ainda que a modifique formalmente, para disfarçar o servilismo da cópia. O disfarce é, mesmo, o meio mais usado pelo plagiário, para tentar enganar não apenas o público em geral, mas, principalmente, o titular dos direitos autorais sobre a obra plagiada. No entanto, o plágio se apura muito mais em função das semelhanças, do que das diferenças, de modo que o próprio disfarce termina sendo a melhor demonstração do dolo, no plágio (MANSO, 1987, pp. 85-86). 
[...] no plágio, a obra alheia é, simplesmente, apresentada pelo imitador como própria, ou sob graus diferentes de dissimulação. Há absorção de elementos fundamentais da estrutura da obra, atentando-se, pois, contra a personalidade do autor (frustração da paternidade). (BITTAR, 1994, p. 150)Do plágio pode-se dizer que é uma pirataria soft ou uma pirataria light, porque o plágio é a cópia de uma obra querendo parecer que não é cópia. A cópia pura e simples, em que a pessoa se substitui ao autor, é a usurpação. O plágio não, o plágio disfarça, não quer ser, não quer parecer o que é (CHAVES, 1997, p. 126, apud COTTA, 2018).

No sentido jurídico do termo, o plágio pressupõe uma imitação servil ou fraudulenta de obra alheia, voltada para a ocultação do texto anterior e do seu autor. O fundamento para a existência desse delito se dá, segundo Bittar (1994, p. 150-151), pela "absorção de elementos fundamentais da estrutura da obra [...], quanto a tema, a fatos, a comentários, a estilo, a forma, a método, a arte, a expressão, na denominada substantial identity". Assim, para que ocorra o plágio, é preciso que haja uma identidade de forma e conteúdo e que a obra tenha sido publicada e assinada pelo plagiário.

Essa prática desrespeita os direitos autorais e, no meio acadêmico, ofende a integridade científica, porque diz respeito diretamente à ética e honestidade na pesquisa. Contudo, o plágio ainda é recorrente em trabalhos de disciplinas de graduação e pósgraduação e em monografias de final de curso, dissertações de mestrado, teses de doutorado e artigos científicos.

O inciso I do art. 43 da Lei de Diretrizes e Bases da Educação Nacional prevê como uma das finalidades do ensino superior "estimular a criação cultural e o desenvolvimento do espírito científico e do pensamento reflexivo" (BRASIL, 2018b), o que é totalmente contrário à prática do plágio, tão presente no cotidiano acadêmico, e, segundo Krokoscz (2011, p. 746), “incompatível com o escopo universitário de criação e desenvolvimento do conhecimento, constituindo-se demanda que requer imprescindível reflexão e posicionamento institucional".

$\mathrm{Na}$ universidade, o plágio não se configura somente como a cópia literal de partes ou da totalidade de textos alheios, o chamado "plágio direto", identificam-se ainda outras modalidades, com maior tendência ao disfarce, à dissimulação, como aponta Krokoscz (2012, p. 43-55):

- Plágio Indireto - paráfrases sem atribuição de crédito, fragmentos de fontes diferentes ou o uso inadequado de expressões clássicas;

- Plágio de Fontes - reprodução de citações sem o uso do termo latino "apud";

- Plágio Consentido - anuência do autor original e a compra de trabalhos;

- Autoplágio - trabalho intelectual reproduzido pelo autor original em situações diferentes, sem indicação de seu não ineditismo.

Como forma de reduzir as ocorrências de plágio e outras fraudes, muitas instituições de ensino e pesquisa propõem intervenções para a detecção de infrações éticas, como o uso de softwares específicos, a educação/ conscientização da comunidade acadêmica, a elaboração de códigos de conduta e a organização de comissões específicas para avaliar casos de suspeita de plágio e más condutas em pesquisa, com previsão de punições aos discentes, docentes e servidores que violem as normas institucionais. A esse respeito, Krokoscz (2011, p.752) salienta que 
enfrentamento que tenham essa característica de globalidade, ou seja, que envolvam os alunos, professores, orientadores e gestores.

As discussões e propostas de intervenção em relação ao plágio na academia são extremamente relevantes e necessárias, uma vez que esse tipo de atitude desonesta, que dissimula o texto-fonte e oculta o nome do autor original, prejudica não só o próprio plagiário, que se vê diante da reprovação moral e descrédito da comunidade científica, mas também a reputação da instituição à qual está associado.

O enfrentamento do plágio precisa passar primeiro pela identificação das motivações para esse ato fraudulento. Dentre elas, considerando os universitários iniciantes, é possível citar a dificuldade de escrita e o desconhecimento das regras de normalização e estilo na comunicação científica, uma vez que estão habituados, desde a educação básica, ao hábito de transcrição literal. Assim é que professores universitários se deparam constantemente com casos de cópia, em sua grande maioria de fontes digitais, daí a necessidade de orientar os estudantes quanto às regras básicas de escrita acadêmica, que incluem normas de reconhecimento e registro das fontes consultadas, considerando que, segundo Diniz e Munhoz (2011, p. 16), "um jovem escritor precisa dominar a cadeia de influências a que está vinculado, e o reconhecimento das ideias anteriores às suas é também uma habilidade que deve ser desenvolvida".

\section{Noções de Autoria e Autoria Científica}

Diversos estudiosos das noções de autor e autoria destacam que, da Antiguidade até a Idade Média, não existia uma reflexão sobre a figura do autor de uma história, pintura, música etc., isto é, várias pessoas que participavam da produção de uma obra (seja ela de que natureza fosse) eram consideradas autoras e não havia nenhum problema aparente nisso.

Muitas histórias míticas da Grécia e Roma antigas não possuem a identificação de seus autores. Era muito comum nessas civilizações que textos fossem escritos por mais de um autor. Alguns historiadores da Filosofia antiga entendem que obras como Ilíada e Odisseia não foram escritas por um só autor chamado Homero, mas por um conjunto de autores, até mesmo, possivelmente, de diferentes épocas. Textos de filósofos antigos e da Idade Média muitas vezes referiam-se a ideias ou teorias já expostas por filósofos anteriores sem fazer referência a estes, pois, nessas épocas, não havia um intuito direto de apropriação de textos ou ideias, mas existia o desejo de confrontar ou corroborar ideias, reflexões ou teorias já divulgadas, e a citação dos filósofos autores era completamente dispensável, por serem "amplamente" divulgadas, já se sabia a quem pertenciam tais pensamentos ou ensinamentos.

Todavia, atualmente, a valorização do autor ou da autoria de uma obra é inegável, especialmente depois da consagração dos direitos autorais, que se dá, principalmente, em razão da agregação de valores de cunho moral, econômico e sucessório às produções intelectuais.

Se hoje, ao nos referirmos a uma obra, estabelecer a relação com a instância autoral é inelutável, outrora não foi assim. Na Antigüidade até o início da Idade Média, não havia a preocupação de estabelecer a responsabilidade pelo fechamento da obra, as histórias estavam em contínuo processo de criação, os contadores tinham o direito de decidir, segundo a sua própria vontade, o que acrescentar, melhorar ou modificar. As narrativas, tragédias, comédias, epopéias - textos, hoje, denominados de literatura - eram postas em circulação e valorizadas sem que se colocasse em questão a autoria, já que o anonimato não constituía um empecilho, a sua própria antigüidade era uma garantia suficiente de autenticidade. Cabe lembrar que a função de autor, de Foucault (2002), não se dá de forma universal e uníssona em todas as 
formas discursivas, mesmo dentro de uma própria cultura, tal como ele nos exemplifica ao diferenciar os distintos desenvolvimentos das obras científicas e das obras literárias (CAVALHEIRO, 2008, p. 68, grifo do autor).

As primeiras preocupações com a autoria de obras iniciaram-se ao final da Idade Média e com o início do Renascimento. Nessa nova fase, surgiram autores e obras literárias, a exemplo, respectivamente, de Dante Alighieri, com a Divina Comédia, Maquiavel, com $O$ Príncipe, e Miguel de Cervantes, com Dom Quixote. Também aparecem pintores como Leonardo da Vinci, Rafael Sanzio e Michelangelo. Ideias importantes surgiram também nesse período, como, por exemplo, as ideias de Nicolau Copérnico em oposição à teoria geocêntrica e as de Galileu Galilei em oposição ao geocentrismo.

O marco decisivo para o nascimento das noções de autor e autoria ocorre no século $\mathrm{XV}$, a partir do surgimento da imprensa, com a tipografia, invenção do alemão Johannes Gutenberg (1398-1468).

A partir da Renascença, observa Foucault (1981), distintos fatores sociais, políticos e econômicos contribuíram para a invenção e a exaltação do indivíduo, o qual, na arte, corresponde à figura do autor. Antes do reconhecimento do direito autoral, os primeiros movimentos para estabelecer a identidade da autoria, como nos ensina Chartier (1999) surgiram na Idade Média. Nesse período, como resultado da censura, livros heréticos eram queimados. Para identificar e condenar os responsáveis pela transgressão, era preciso designá-los como autores - quem era incumbido pela assinalação dos transgressores e dos nomes dos autores eram as autoridades religiosas e políticas (CAVALHEIRO, 2008, p. 68).

Portanto, é efetivamente na Modernidade que as noções de autor, autoria, e consequentemente, de propriedade intelectual começam a ser consolidadas. Desde então, a figura do autor ganha importância, sobretudo pela valorização financeira da produção de obras, livros, músicas etc. Com as revoluções industriais, técnicas foram sendo cada vez mais aprimoradas para a reprodução de produções intelectuais, a exemplo de máquinas de fotocópias e, posteriormente, com o surgimento da Internet, as divulgações de obras acadêmicas ficaram cada vez mais acessíveis a todo e qualquer público.

Os conceitos de autor e autoria também se confundem em alguns aspectos. Só é possível existir autoria quando há a figura de um autor ou autores idealizando ou produzindo algo. Cavalheiro $(2008$, p. 69) usa o termo 'autor' em seu texto para se referir especialmente aos "instauradores de discursividade", assim como, na pós-modernidadade, enuncia Foucault, para quem "há duas noções que preservam a existência do autor: a noção de obra e a noção de escrita" (CAVALHEIRO, 2008, p. 70), de modo que o autor estaria relacionado a uma pessoa e a autoria com a obra.

O autor é visto de forma individual (autoria individual) como aquele que originou uma ideia, elaborou um texto ou criou uma música etc., e "a princípio há que se ter claro que o autor a quem se atribui o esforço intelectual para a criação de uma obra, sendo o titular originário desta, pode, eventualmente, transferir no todo ou em parte seus direitos para terceiros" (WACHOWICZ; COSTA, 2016, p. 28). No entanto, a autoria, além de individual, pode ocorrer de forma coletiva ou em colaboração, como sé possível constatar nos dias atuais, com bastante incidência nas produções acadêmicas.

No ambiente acadêmico-científico, além de autorias individuais, é bastante recorrente a autoria coletiva ou em colaboração, mas o que permite distinguir duas modalidades autorais: uma autoria científica e uma autoria literária ou patrimonial, é, dentre outras características, principalmente o fato de "ser caracterizada pela recompensa moral e não monetária", segundo Biagioli (2003 apud KROKOSCZ, 2015, p. 91). 
A autoria científica ocorre em um contexto específico de produção de textos, que são veículos de resultados de pesquisas validados e aceitos e, por isso, possuem padronização canônica e obedecem a regras fixas de linguagem. Ademais, nesse tipo de autoria, conforme Krokoscz (2015, p. 87), cabem alguns questionamentos:

[...] quem de fato poder ser considerado autor em um trabalho científico? Quantas pessoas podem ser elencadas como autores? Como estabelecer parâmetros que determinem de forma objetiva a elegibilidade de alguém como autor em um trabalho científico? Como definir a importância autoral científica em um trabalho com vários autores? Quais são os princípios éticos que norteiam a autoria científica? O que caracteriza um autor científico?

Muitas dessas questões ainda não possuem respostas, o que, em certa medida, é um problema, principalmente se se considerar ocorrências de más condutas em pesquisa, plágio ou outros tipos de fraude. Se há uma acusação de plágio, por exemplo, a um trabalho assinado por um grupo de pesquisadores, a quem caberia a responsabilidade por esse ato doloso? Quem responderia civil e penalmente por esse delito? Todos os autores ou somente aquele que, na parte da produção textual que lhe competia, não citou as fontes?

\section{Considerações sobre Letramento Acadêmico}

No Brasil, discussões em torno do baixo rendimento no desempenho de alunos da educação básica em relação às competências linguístico-discursivas têm sido profícuas, gerando reflexões e ações, em âmbito nacional, para preencher lacunas e sanar os problemas/ dificuldades.

As práticas de leitura e escrita são práticas sociais, o que justifica o fundamental papel da escola para que o desempenho linguístico dos alunos não dificulte a aprendizagem de outras matérias e permita que alcancem competências necessárias para agirem em sociedade. Assim, as competências para ler e escrever devem estar inseridas na rotina escolar, de modo a formar cidadãos críticos, que, mais do que reproduzir conceitos, sejam capazes de compreendê-los, interpretá-los e relacioná-los, fazendo uso de múltiplos letramentos.

É notório que, ao saírem do Ensino Médio, muitos alunos ainda apresentem graves dificuldades no processo de recepção e produção de textos, seja porque não são suficientemente capacitados para tal, seja porque, às vezes, a aprendizagem é separada do uso, descontextualizada, portanto.

A problemática que envolve os baixos rendimentos em leitura e escrita dos alunos da educação básica, especialmente daqueles advindos das camadas populares, reflete-se significativamente no ensino universitário, por um lado porque, como dito anteriormente, não possuem habilidades linguísticas, textuais e discursivas suficientes, e, por outro, porque desconhecem a escrita e o discurso acadêmico, com os quais são solicitados a interagir.

Ao ingressar no nível superior, uma nova realidade é apresentada aos alunos, um universo sociocultural, linguístico, discursivo e pragmático que lhes causará estranhamento e dificuldades. É assim que Souza (2012, p. 156) afirma e questiona: “Os textos acadêmicos [...] não pertencem às práticas de letramento dos alunos antes de estes ingressarem na universidade. Tendo isso em conta, como esperar de nossos alunos proficiência de leitura e escrita de gêneros textuais que nem sequer (re)conhecem?"

Diante desse contexto, não se espera que os alunos recém-inseridos na academia e nem os pós-graduandos possuam todas as habilidades e competências necessárias para a leitura e escrita científica, mas é possível promovê-las por meio do letramento acadêmico, um processo de desenvolvimento de práticas e comportamentos sociais, em interação com a 
escrita, focalizando as "relações entre poder, autoridade, produção de sentido e identidade" em nível superior, como apontam Lea e Street (2006).

Essa concepção da escrita como prática social, defendida pelos pesquisadores dos Novos Estudos do Letramento - NEL e conforme o modelo ideológico proposto por Street (1984), considera que as práticas letradas são resultantes do contexto sociocultural que as circundam, dos significados que lhes são atribuídos em diferentes instituições e grupos sociais e das relações de poder relativas ao seu uso. Dessa forma, assume-se que as práticas de escrita são adequadas a cada um de seus contextos de uso, sendo possível distinguir, como observa Juchum (2014, p. 112), "usos específicos da escrita no contexto da universidade, usos que diferem de outros contextos".

O letramento acadêmico constitui-se, portanto, em um desafio aos alunos, pesquisadores e docentes, na medida em que, ao apresentar a cultura acadêmico-científica, exige adaptação a novas formas de acesso, compreensão, interpretação, organização e divulgação do conhecimento, o que acaba por gerar conflitos entre as expectativas dos professores em relação ao que esperam dos textos escritos que lhes são entregues e o que os alunos efetivamente escrevem (LEA; STREET, 1998).

No âmbito desses conflitos, a pouca familiaridade com os gêneros e a escrita acadêmica torna-se uma questão bastante complexa para alunos de graduação, e também de pós-graduação, que reclamam da dificuldade de produzir textos criativos, originais ou inéditos, subordinados às normas da linguagem e estilo acadêmicos, de modo que, muitas vezes, pelo hábito de reprodução textual desde $\mathrm{o}$ ensino fundamental e/ou o desconhecimento das normas de citação e referenciação de fontes, acabam por entregar aos professores o que se configura como plágio.

Desta forma, é necessário que se inclua na formação do discente universitário uma discussão relativa ao plágio como ação ilícita que transgride os direitos autorais e a integridade científica e uma abordagem mais consistente sobre o processo de produção de textos acadêmicos, com atenção às regras de normalização e estilo na comunicação científica, como forma de enfrentamento dessa prática dolosa.

\section{Relação entre Ciência e Escrita}

A pesquisa, ferramenta indispensável na rotina acadêmica, especialmente no ensino público, visa não somente buscar, produzir e divulgar conhecimento, mas também fomentar o próprio ensino/aprendizagem de seus fundamentos e métodos, tornando-se peça chave na construção da autonomia intelectual e da consciência crítica do discente. A pesquisa é, portanto, um princípio científico e educativo, "essencialmente dialógica, sistemática, metodologicamente organizada, implica a socialização de saberes e acontece na linguagem [...], não sendo possível fora dela" (FERREIRA, 2009, p. 275).

O ingresso no universo da ciência, que se dá por meio da pesquisa, é um processo lento, especializado e extremamente complexo, que demanda, dentre outras coisas, uma nova forma de relação com a leitura, muito mais analítica e crítica, e uma prática constante de escrita de gêneros textuais próprios ao domínio discursivo acadêmico. Assim, pode-se afirmar que leitura e escrita, etapas fundamentais da produção do conhecimento, são indissociáveis da pesquisa científica.

De acordo com Pereira (2013, p. 216), "o que distingue a ciência das demais naturezas de saber é justamente a sua forma de escrita", ancorada em uma linguagem própria para validar o conhecimento produzido. Esse tipo de linguagem científica estabelece uma série de regras, a exemplo do uso da clareza, objetividade e impessoalidade, para se alcançar certo rigor, neutralidade e universalização. Ademais, cabe destacar que o discurso científico se sustenta em outros discursos, em outras vozes e textos, sendo fruto de influências e 
interações, conforme a perspectiva bakhtiniana de "polifonia" (BAKHTIN, [1979] 1997). No entanto, exige-se que essas outras vozes, que dão validade à pesquisa, sejam identificadas no texto, que se dê o devido crédito às fontes consultadas: "O texto deve convencer; as notas, as citações e as referências devem "provar"', como salienta Grafton (1998, p. 25 apud PEREIRA, 2013, p. 218).

Nota-se, contudo, que proceder à citação e referenciação de autores e textos é algo incomum na produção textual de grande parte dos discentes do ensino fundamental ao ensino superior, porque está historicamente arraigada ao ensino brasileiro a prática da cópia de textos alheios, parcial ou total, sem a indicação das fontes. Essa ação é totalmente estigmatizada pela comunidade acadêmico-científica, uma vez que se configura como violação aos direitos autorais e à integridade da ciência.

A partir do exposto, evidencia-se a importância do desenvolvimento do letramento acadêmico, com especial atenção às competências escritas, sob um ponto de vista sociointerativo.

\section{Promovendo o Letramento Acadêmico contra o plágio na UFS}

Em pesquisa realizada em 2011 a respeito da abordagem do plágio nas três melhores universidades de cada um dos cinco continentes e do Brasil, Marcelo Krokoscz, doutor e mestre em Educação pela Universidade de São Paulo e professor-pesquisador do Centro Universitário da Fundação Escola de Comércio Álvares Penteado (FECAP), em São Paulo, detectou que muitas universidades, especialmente as internacionais, adotam medidas institucionais e preventivas de enfrentamento dessa prática, considerando inclusive a adoção de Códigos de Honra ou a implantação de Centros de Integridade Acadêmica ou Comissões de Ética.

No Brasil, como o mesmo pesquisador aponta, "a pesquisa acadêmica e o debate sobre o plágio ainda são incipientes" (KROKOSCZ, 2011, p. 745). O reflexo disso é que as três melhores universidades brasileiras daquele ano (Universidade de São Paulo, Universidade Estadual de Campinas e Universidade Federal de Santa Catarina) não apresentavam em seus sites institucionais documentos oficiais sobre o plágio.

Diferentemente do que foi comprovado por Krokoscz há sete anos nas melhores universidades do país, a Universidade Federal de Sergipe apresenta abordagens sobre o plágio em sua homepage, o que foi comprovado por uma busca eletrônica no mês de maio de 2018. Foi possível identificar algumas ações preventivas, especialmente de orientação e capacitação da comunidade acadêmica. Nessas ações de prevenção de fraudes em pesquisa, destacam-se as iniciativas da Coordenação de Pesquisa - COPES e da Coordenação de Inovação e Transferência de Tecnologia - CINTTEC, como, por exemplo, um dos tópicos de orientação para orientadores para a submissão de projetos PIBIC, de acordo com o qual os planos de trabalho que apresentem plágio serão desclassificados, além da indicação de acesso aos documentos que tratam da legislação brasileira e institucional sobre propriedade intelectual e dos minicursos ofertados todos os anos aos bolsistas de iniciação científica e tecnológica, tais como "Redação científica e plágio acadêmico", "Gerenciamento de referências bibliográficas", "Noções básicas de propriedade intelectual", "Propriedade intelectual: noções básicas e novidades legais", "E aí plagiei? Noções básicas de Direito Autoral" e "Propriedade Intelectual e Direito Patentário: motivos e consequências da quebra de patentes".

Ainda em relação ao conteúdo institucional de enfrentamento do plágio da UFS, há que se considerar o disposto na Resolução No 09/2016/CONEPE, que busca promover e manter uma cultura de integridade científica, através de medidas preventivas, diagnósticas e corretivas contra o plágio e a contrafação. 
Entretanto, apesar do incentivo institucional da Universidade Federal de Sergipe ao enfrentamento do plágio, esse ainda é um assunto que precisa ser mais discutido em sala de aula e nos grupos de pesquisa de graduação e pós-graduação, não somente para conscientizar a comunidade acadêmica sobre as consequências danosas dessa prática para a integridade científica, mas também de modo a instrumentalizar os docentes em suas ações diante de trabalhos fraudulentos e os discentes para boas práticas em pesquisa.

Nesse viés, a partir de uma postura ética de prevenção do plágio e seguindo a recomendação do grupo de pesquisadores do Second Brazilian Meeting on Research Integrity, Science and Publication Ethics, de que as instituições brasileiras devem conscientizar "os alunos de que o plágio é uma violação acadêmica [...]" e proporcionar "atividades educativas [...] entre alunos e professores [...]" (BRISPE, 2018, p. 556), e a orientação disposta no Art. 14 da Resolução No 09/2016/CONEPE da UFS, segundo a qual "É responsabilidade da instituição a promoção de eventos organizados por seus servidores docentes e técnicoadministrativos para contribuir continuamente com a educação e prevenção contra a contrafação e o plágio na academia" (UFS, 2018, p. 3), promoveu-se o projeto de extensão intitulado "Plágio Acadêmico: o que é e como evitá-lo" (em vigência de 09 de julho a 09 de novembro de 2018), que visa proporcionar a estudantes de graduação dos diversos cursos da Universidade Federal de Sergipe, campus de São Cristóvão, medidas educativas de conscientização sobre o plágio e as boas condutas no ambiente universitário, capacitando-os para a produção de textos acadêmicos e promovendo, assim, através do letramento acadêmico, a integridade científica.

A proposta apresentada nasceu e tem identificação com a metodologia desenvolvida na disciplina de Produção e Recepção de Texto II, ofertada pelo Departamento de Letras Vernáculas da UFS. Nessa disciplina, os primeiros tópicos de aula abrangem discussões de questões como as modalidades de graduação e pós-graduação, caracterização das dissertações de grau, a finalidade da educação superior, com foco na produção e difusão de conhecimentos, a ética em pesquisa, conceito, configurações e motivações do plágio, as normas de citação e referenciação e as normas da ABNT para trabalhos acadêmicos.

Um projeto como esse é fundamental para uma maior reflexão a respeito da "importância do compromisso e desenvolvimento de princípios éticos" em pesquisa, como destaca Krokoscz (2011, p.760), a formação de sujeitos conscientes de que o plágio, assim como a contrafação ou a compra e venda de trabalhos, são violações acadêmicas e práticas ilegais em qualquer nível de ensino (fundamental, médio ou universitário), além do desenvolvimento de competências linguísticas e textuais necessárias "para a comunicação responsável da ciência e seus resultados para seus pares e para a sociedade" (BRISPE, 2018, p. 556).

O mencionado projeto visa ainda estimular a produção de artigos, ensaios, comunicações etc. sobre plágio e violação de direitos autorais pelos discentes/monitores envolvidos na ação de extensão, bem como tem por escopo primordial, ao final da ação, a produção e disponibilização de material impresso e eletrônico educativo que buscará conscientizar a comunidade acadêmica da UFS sobre os prejuízos que podem ser causados ao bom nome da instituição pela prática do plágio acadêmico.

\section{Conclusão}

O plágio acadêmico ainda é uma prática muito comum no sistema educacional brasileiro. A violação de direitos autorais é vista muitas vezes pelos discentes, mas também por alguns docentes, como um ato tolerável, sem que sejam refletidas as reais consequências dessa prática. No âmbito das universidades brasileiras, a cultura do publish or perish apenas 
contribui para que o plágio aconteça, a pesquisa careça de originalidade, ineditismo e credibilidade, não agregando novos conhecimentos.

Embora a Lei $n^{\circ}$. 9.610/98 seja um importante instrumento jurídico de enfrentamento das práticas que violem os direitos autorais, não apresenta uma conceituação precisa do que seja o plágio, cabendo tal conceituação aos doutrinadores jurídicos e aos pesquisadores linguísticos sobre o tema.

A reflexão sobre a ética na pesquisa e a conscientização acadêmica devem ser realizadas de forma séria a fim de que haja o devido respeito à autoria das produções científicas, e que as reputações do pesquisador e da instituição a qual esteja vinculado sejam preservadas e o ensino brasileiro possa se desprender do velho "jeitinho brasileiro" e alcance o devido reconhecimento em âmbito mundial.

\section{Referências}

ASCENSÃO, José de Oliveira. Direito Autoral. Rio de Janeiro: Forense, 1980.

BAKHTIN, Mikhail. [1979]. Estética da Criação Verbal. Trad. Maria Ermantina Galvão G. Pereira. 2. ed. São Paulo: Martins Fontes, 1997.

BITTAR, Carlos Alberto. Direito de Autor. 2. ed. rev. e atual. Rio de Janeiro: Forense Universitária, 1994.

BRASIL. Lei No 9.610, de 19 de fevereiro de 1998. Disponível em:

$<$ http://www.planalto.gov.br/ccivil_03/leis/L9610.htm>. Acesso em: 23 abr. 2018a.

BRASIL. Lei de Diretrizes e Bases da Educação Nacional - LDB: lei nº 9.394, de 20 de dezembro de 1996, que estabelece as diretrizes e bases da educação nacional. 5. ed. Brasília: Câmara dos Deputados, Coordenação Edições Câmara, 2010. Disponível em:

$<$ http://bd.camara.gov.br>. Acesso em: 30 abr. 2018 b.

BRISPE. Second Brazilian Meeting on Research Integrity, Science and Publication Ethics. Rio de Janeiro, São Paulo, Porto Alegre (May 28 - June 1, 2012). Disponível em:

$<$ http://www.iibrispe.coppe.ufrj.br/>. Acesso em: 18 mai. 2018.

BURKE, Peter. Uma História Social do Conhecimento: de Gutenberg a Diderot. Trad. Plínio Dentzien. Rio de Janeiro: Zahar, 2003.

CARVALHO, Isabel Cristina Louzada; KANISKI, Ana Lúcia. A sociedade do conhecimento e o acesso à informação: para que e para quem? Ci. Inf., Brasília, v. 29, n. 3, p. 33-39, set./dez. 2000.

CAVALHEIRO, Juciane dos Santos. A concepção de autor em Bakhtin, Barthes e Foucault. Sigmund: Estud. Ling., Londrina, n. 11/2, p. 67-81, dez. 2008. Disponível em:

<www.uel.br/revistas/uel/index.php/signum/article/view/3042>. Acesso em: 12 jul. 2018.

COTTA, André Guerra. O Palimpsesto de Aristarco: considerações sobre plágio, originalidade e informação na musicologia histórica brasileira. Perspect. ciênc. inf. Belo Horizonte, v. 4, n. 2, p. 184-209, jul./dez. 1999. Disponível em:

$<$ www.eci.ufmg.br/pcionline/index.php/pci/article/viewFile/567/532>. Acesso em: 10 mai. 2018.

DINIZ, Débora; MUNHOZ, Ana Terra Mejia. Cópia e pastiche: plágio na comunidade científica. Argumentum, Vitória (ES), ano 3, v. 1, n. 3, p. 11-28, jan./jun. 2011.

FERREIRA, Liliana Soares. A pesquisa e a escrita na Universidade: sistematizando uma prática pedagógica em aulas de metodologia da pesquisa e pesquisa em Educação. Cadernos de Educação, FaE/PPGE/UFPel, Pelotas [32]:267-284, jan./abr.2009.

FÓRUM de Reflexão Universitária. Os desafios da pesquisa no Brasil. Caderno Temático do Jornal da Unicamp, Campinas, ano I, n. 12, p. 1-4, fev. 2002. JORGE, Carlos Jorge Figueiredo. A Problemática do Plágio como Questionamento da Transtextualidade. Análise da relação literária de "O Crime do Padre Amaro" com "La 
Faute de 1'Abbé Mouret'. 474 f. 1997. Tese (Doutorado em Literatura Comparada) Universidade de Évora, Évora, 1997.

JUCHUM, Maristela. A escrita na universidade: uma reflexão com base no que os alunos dizem em seus textos. Horizontes de Linguística Aplicada, ano 13, n.1, p. 107-129, 2014. KROKOSCZ, Marcelo. Abordagem do plágio nas três melhores universidades de cada um dos cinco continentes e do Brasil. Revista Brasileira de Educação, v. 16, n. 48, , p. 745-818, set./dez. 2011.

KROKOSCZ, Marcelo. Autoria e Plágio: um guia para estudantes, professores, pesquisadores e editores. São Paulo: Atlas, 2012.

KROKOSCZ, Marcelo. Outras Palavras Sobre Autoria e Plágio. São Paulo: Atlas, 2015.

LEA, Mary R.; STREET, Brian V. Student writing in higher education: an academic literacies approach.UK Studies in Higher Education, v. 23, n. 2, p. 157-172, 1998.

LEA, Mary R.; STREET, Brian V. The "Academic Literacies" model: theory and applications. Theory into Practice, v. 45, n. 4, p. 368-377, 2006.

MANSO, Eduardo J. Vieira. O que é Direito Autoral. São Paulo: Brasiliense, 1987 (Coleção Primeiros Passos, 187).

MOTTA-ROTH, Désirée; HENDGES, Graciela Rabuske. Produção Textual na

Universidade. São Paulo: Parábola, 2010.

PEREIRA, Elisabete Monteiro de Aguiar. A construção do conhecimento na modernidade e na pós-modernidade: implicações para a universidade. Revista Ensino Superior, n. 14, jul./set. 2014. Disponível em: <https://www.revistaensinosuperior.gr.unicamp.br/artigos/aconstrucao-do-conhecimento-na-modernidade-e-na-pos-modernidade-implicacoes-para-auniversidade>. Acesso em: 09 ago. 2018.

PEREIRA, Marcos Villela. A escrita acadêmica - do excessivo ao razoável. Revista

Brasileira de Educação, v. 18, n. 52, p. 213-244, jan./mar. 2013.

SOUZA, Clinio Jorge de. Letramento Acadêmico: da escrita à leitura científica. Anúncio da Produção Acadêmica Docente, Faculdade Anhanguera de Sorocaba, v. 6, n. 15, p. 155-172, 2012.

STREET, Brian. Literacy in theory and practice. London: Cambridge University Press, 1984.

STREET, Brian. Letramentos Sociais: abordagens críticas, do letramento no desenvolvimeto, na etnografia e na educação. Trad. Marcos Bagno. São Paulo: Parábola, 2014.

UFS. Resolução No 09/2016/CONEPE. Disponível em:

$<$ https://www.sigaa.ufs.br/sigaa/public/programa/documentos.jsf?lc=pt_br\&id=241\&idTipo= 3>. Acesso em: 22 mai. 2018.

WACHOWICZ, Marcos; COSTA, José Augusto Fontoura. Plágio acadêmico. Curitiba:

Gedai Publicações/UFPR, 2016. 224p. Disponível em:

$<$ https://ibpieuropa.org/?media_dl=767>. Acesso em: 13 jul. 2018.

Submetido em 26/09/18

Aceito em 10/12/2018 